Review Article

\title{
Complexity Analysis for Price Competition of Agricultural Products with Regional Brands
}

\author{
Haolong Liu $\mathbb{D}^{1},{ }^{1}$ Xin Su, ${ }^{1,2}$ Xiaohui Wang, ${ }^{3}$ and Xiao Li $\mathbb{D}^{4,5}$ \\ ${ }^{1}$ School of Business Administration, Shandong University of Finance and Economics, Jinan 250014, China \\ ${ }^{2}$ Research Center of Government Performance Evaluation, Shandong University of Finance and Economics, Jinan 250002, China \\ ${ }^{3}$ Department of Finance and Economics, Shandong College of Electronic Technology, Jinan 250200, China \\ ${ }^{4}$ Zhejiang University of Water Resources and Electric Power, Hangzhou 310018, China \\ ${ }^{5}$ College of Management and Economics, Tianjin University, Tianjin 300072, China
}

Correspondence should be addressed to Haolong Liu; hlliu161031@126.com and Xiao Li; xiaoli20180828@126.com

Received 21 May 2021; Accepted 16 July 2021; Published 23 July 2021

Academic Editor: Lijun Pei

Copyright $\odot 2021$ Haolong Liu et al. This is an open access article distributed under the Creative Commons Attribution License, which permits unrestricted use, distribution, and reproduction in any medium, provided the original work is properly cited.

\begin{abstract}
The disordered price competition among various agricultural business agents leads to chaos of agricultural products' prices, which makes it difficult for customers to form stable price expectation and correct brand cognition, restricting the sales of agricultural products with regional brands. Based on the Salop circular market model with bounded rationality and delayed feedback, this paper discusses the complexity in price competition of agricultural products with regional brands. It is found that when the price adjustment speed of agricultural business agents exceeds the stability region, the pricing system of agricultural products with regional brands would appear the phenomenon of periodic bifurcation or chaos. The delayed feedback controlling mechanism of price adjustment could make the pricing system in the chaos state turn to the equilibrium state. Therefore, the price fluctuation of agricultural products with regional brands needs reasonable control from the industrial associations and government departments.
\end{abstract}

\section{Introduction}

With the rapid development of economy and the continuous improvement of living standards, Chinese people pay more and more attention to the quality of agricultural products. A regional brand of agricultural products usually refers to the name or symbol of agricultural products known and recognized by customers according to the unique natural resources, reasonable cultivating methods, and advanced processing techniques. In China, the regional brands of agricultural products usually appear in forms of geographical indications. Many agricultural products with regional brands are named by the combination of a regional name and a category name, such as "Wuchang Rice," "Yantai Apple," and "Yangcheng Lake Hairy Crab", which have high brand awareness and reputation.

Empirical evidence shows that strengthening the construction of agricultural regional brand could effectively promote the agricultural modernization and supply-side reform and then increase the farmers' income. China's "National Strategic Plan for Promoting Agriculture with High Quality" (2018-2022) proposes that it is necessary to promote the construction of agricultural regional brand and create more advantageous characteristic agricultural products. No.1 central documents of the Chinese Central Government in recent 5 years have repeatedly stressed the significance to improve the certification and management of agricultural products' geographical indications and to ensure customers' confidence in agricultural products' quality by the construction of high-quality regional brands. By the beginning of 2021, China has registered 3200 geographical indications of agricultural products.

In general, the awareness to develop regional brands of agricultural products in China has been enhanced, and the construction of regional brands has achieved remarkable results. However, the regional brands of agricultural 
products have significant attributes of public goods. While benefiting from the premium of regional brands, various agricultural business agents in a specific region also have responsibilities to abide by the quality standards of regional brands and to actively maintain the good image of regional brands. However, there are serious free-riding problems in the construction and management of the agricultural regional brands, leading to the tragedy of the commons in different forms. In particular, the disordered price competition among various agricultural business agents in a specific region leads to the pricing chaos of agricultural products, making it difficult for the customers to form stable price expectations and correct brand recognition. It not only damages the image of regional brands but also causes many problems of market failure. Finally, the disordered price competition would hinder the sales of agricultural products with regional brands.

In fact, the price competition of agricultural products in a specific region mainly occurs between modern and traditional agricultural business agents, forming a special duopoly competition process. On the one hand, the modern agricultural business agents with the competitive advantages of specialization, represented by professional cooperatives, have become the main suppliers of agricultural products with regional brands. On the other hand, the traditional agricultural business agents represented by small- and medium-sized farmers have become an independent market force by the genealogical and geographical proximity, which means they tend to take the same pricing strategies simultaneously. Therefore, the price competition of agricultural products within a specific region is extremely similar to the duopoly competition between the modern agents and the traditional groups. It is of great theoretical and practical significance to analyze the price competition complexity of agricultural products with regional brands by improving the duopoly competition models.

\section{Literature Review}

The traditional duopoly competition models, such as Cournot models, Stackelberg models, and Bertrand models, are mostly based on the assumption of complete rationality and complete information to discuss the static equilibrium, which has limitation in dealing with the complex and dynamic economic environment. In order to make up for the above shortcomings, the dynamic duopoly competition models based on bounded rationality gradually relaxes the assumptions of complete rationality and complete information and introduces the analysis framework of nonlinear dynamic systems, which describes the complex phenomenon of dynamic evolution more clearly $[1,2]$.

In the early research studies, focusing on the dynamic process of duopoly games, the scholars analyzed the possible complex phenomena such as periodicity and chaos and explored the evolution process of multiagent dynamic games by revealing the stability conditions of the equilibrium points [3-5]. Then, the scholars further relaxed the assumptions, discussed the dynamics of the duopoly competition under the conditions of bounded rationality and self-adaptability, proposed a general analysis framework to deal with the complexity issues with the theories of nonlinear dynamic systems, and used bifurcation, strange attractor, max Lyapunov exponents, and other dynamic characteristics to discuss the complexity of the system [6-8].

By numerical simulation, the scholars proposed that the high-speed strategic adjustment based on the marginal profit, as well as the tiny variation of crucial parameters, might cause the periodic bifurcation and chaos in the dynamic system and found that the delayed feedback control mechanism could improve the probability to reaching equilibrium $[9,10]$. In recent years, scholars focused on the price competition game under the condition of bounded rationality, put forward the dynamic evolution characteristics of the Bertrand and Hotelling duopoly competition model, analyzed the existence and stability conditions of the system equilibrium points, and found that increasing the speed of price adjustment would lead to instability and even chaos [11-13].

The above research studies provide instructive references for the complexity analysis of the price competition of the agricultural products with regional brands, but there are still some problems to be discussed and solved. Firstly, because the agricultural production function is relatively stable and the land resources are very scarce, it is difficult for agricultural business agents in a specific region to adjust the production input and output immediately [14]. At the same time, various agricultural business entities have different production technologies, leading to significant heterogeneity of agricultural products [15]. Therefore, the price competition model based on attribute difference is more suitable for the complexity analysis for price competition of agricultural products with regional brands [16-19]. Secondly, the existing research studies have not comprehensively explained the causes of the bounded rationality and the prerequisites of the delayed feedback control mechanism in a specific situation based on the economic theory. In fact, the traditional agricultural business agents represented by smalland medium-sized farmers have obvious characteristics of bounded rationality in production and pricing, which results in the misbehaving of endowment effect, myopic loss aversion, and excessive risk aversion [20, 21]. However, the technical criterions and pricing levels of modern agricultural business agents represented by professional cooperatives are strictly controlled by the industrial associations and government departments, and the price adjustment process has typical characteristics of delayed feedback control [22-26].

Therefore, the price competition model with quality difference, bounded rationality, and delayed feedback control is more conducive to the complexity analysis for price competition of agricultural products with regional brands [27-31]. Based on the theories of signal transmission and public goods, this paper explores the behavior characteristics of heterogeneous agents and demonstrates the origin of chaos in price competition of agricultural products with regional brands. Then, this paper establishes the Salop circular market model with bounded rationality and delayed feedback, simulates the complexity in price competition of agricultural products with regional brands, and explains the 
pricing control mechanism according to the variation of parameters [32].

\section{Theoretical Analysis}

3.1. Signal Transmission and Premium Effects. Due to the attributes of credence goods, it is difficult for customers to fully understand the real quality information of agricultural products, so the signal recognition and transmission mechanism is necessary to manifest the attributes of highquality agricultural products [33]. As an identification mechanism, the geographical indications of agricultural products could transmit the attribute and origin information to customers and provide an implicit quality commitment. After purchasing the high-quality agricultural products with regional brands, customers would acquire higher perceived value, inspiring their repeat purchasing, strengthening their brand association, and promoting the spread of brand reputation. As a result, the search cost for purchasing highquality agricultural products comes down, and the efficiency of production regulation from industrial associations and government departments gets improved.

Therefore, the regional brands of agricultural products would constantly transmit attribute signals to maintain customer loyalty. Due to the high reputation, the prices of agricultural products with regional brands are often higher than the ordinary ones [34]. On the one hand, various agricultural business agents are eager to make up for the extra quality input in the production process through higher prices. On the other hand, in order to reduce the opportunity cost, they need higher prices to improve the marginal profit. The premiums would encourage agricultural business agents to provide high-quality agricultural products with regional brands to the market. Take "Daxing Watermelon" as an example, after registering the geographical indication, the price of this kind of watermelon reached 13 yuan per kilogram, five times higher than that of similar products, but still in short supply.

3.2. Public Goods and Spillover Effects. A regional brand of agricultural products refers to the public brand of a certain category of agricultural products in a specific region, which has the attributes of regionality, externality, and nonexclusivity $[35,36]$. On the basis of the pure public goods and the private goods, the scholars put forward the concept of quasi-public goods, which could be further divided into club products and common resources. As mentioned above, depending on the unique natural and social resources, the regional brands of agricultural products have strong regionality and are jointly owned by agricultural producers in a specific region, showing obvious noncompetitiveness in a certain range. However, for the agricultural producers outside the specific region, the regional brands of agricultural products manifest strong exclusiveness due to nontransferability. This determines that the agricultural products with regional brands are quasi-public goods between pure public goods and private goods. Therefore, the owners of regional brands are not specific agricultural producers, but industrial associations and government departments that represent all agricultural business agents in a specific region. Only the qualified agricultural business agents who obtain the authorization from industrial associations and government departments could use the regional brands and then share the premium of the regional brand.

However, sharing benefits is often not a sufficient and necessary condition for the generation and maintenance of collective actions. In fact, it is difficult for various agricultural business agents to form rational collective actions to develop regional brands of agricultural products. Because of the quasi-public attribute, the management of regional brands faces serious dilemmas, such as free-rider problems and negative externality, which lead to the tragedies of the commons in multifarious forms. Different from the industrial products, it is difficult to establish an efficient supervision and tracing mechanism of agricultural products, which means some producers' opportunistic behaviors could implicate the others who share regional brands, resulting in the rapid decline of collective reputation. For example, for the sake of their own interests, some agricultural producers might reduce the quality standards and selling prices, which would arouse customers' query and lead to the spread of negative word-of-mouth. The disordered price competition makes it difficult for customers to form stable price expectation and correct brand cognition, damaging the images of regional brands and restricting the sales of agricultural products.

\subsection{Behavioral Characteristics of Heterogeneous Agents.} In the process of agricultural modernization in China, there are two categories of agricultural product producers using regional brands: one is the ordinary farmers with authentic production techniques, and the other one is the modern agricultural business agents represented by professional cooperatives. The formation and maintenance of regional brand reputation of agricultural products depend on the organization degree of agricultural production. In the case of large-scale producers, the stronger the private attributes of regional brands, the easier it is to form and maintain regional reputation. In the case of small-scale producers, the stronger the public attributes of regional brands, the more difficult it is to form and maintain regional reputation.

For ordinary farmers, with the gradual improvement of production and sales standards of agricultural products with regional brands, it is difficult to reach the threshold of largescale operation limited by the resource endowments. At the same time, due to the low cost of reputation loss, ordinary farmers usually take a variety of opportunistic behaviors, which violate the price regulations of industrial associations and government departments. Restricted by myopic loss aversion, excessive risk aversion, and other behavioral decision-making characteristics of ordinary farmers, the blind pursuit of interests would lead to their lack of motivation to maintain the pricing stability [37-39].

For the modern agricultural business agents such as professional cooperatives, the foundation of production technology and resource endowment is solid. From the 
combination of farmers and social capitalism, the modern agricultural business agents need to consider the long-term welfare of farmers in a specific region and actively abide by the pricing regulations from industrial associations and government departments, which make their behavioral decision-making more rational. At the same time, through a series of mobilization activities, the professional cooperatives would guide farmers to gradually form regional brand awareness and jointly maintain the reputation of regional brands.

\section{Model Building}

Suppose there is the Salop circular market with perimeter of 2 , on which the traditional and modern agricultural business agents are randomly distributed, producing agricultural products with regional brands which could be completely replaced in function. The traditional agricultural business agents are represented by ordinary farmers, and modern agricultural business agents are represented by professional cooperatives. At point $L$ on the left end, there is a typical ordinary farmer who uses completely traditional methods to cultivate agricultural products. At point $R$ on the right end, there is a typical professional cooperative which adopts completely modern methods to cultivate agricultural products. The model of the Salop circular market is shown in Figure 1.

In reality, there is no agricultural business agent which completely adopts or abandons the traditional or modern production techniques, so most of the agricultural agents are located in the $\operatorname{arc}$ from point $L$ to point $R$. It is assumed that there is an atypical ordinary farmer at point $A$ and an atypical professional cooperative in point $B$, using both of traditional and modern production techniques to cultivate agricultural products with regional brands. The difference of production techniques and product attributes between ordinary farmers and professional cooperatives is reflected in the difference of their location value in the circular market [40-43].

In the marketing practice of agricultural products with regional brands, it could be found that the customer preference is often multidimensional and complex. The customers are often convinced that the production process and techniques of traditional agricultural business agents are more authentic, but their agricultural products might have higher quality and safety risks. The production process and techniques of modern agricultural business agents are safer, but the taste and texture might be less authentic [44-47]. In brief, no matter which kind of agricultural business agents the customers buy agricultural products from, customers would bear certain psychological utility loss, which constitutes the customer's deviation cost.

Therefore, when the customers buy agricultural products, they need to pay two kinds of costs for each purchase: one is the price cost, and the other is the deviation cost. It is assumed that the customers are uniformly distributed in the circular market, there is no special preference for the attribute location value, and the distance from $\mathrm{M}$ to $\mathrm{L}$ is $\mathrm{m}$. When customers choose the supplier at point $A$, they need to

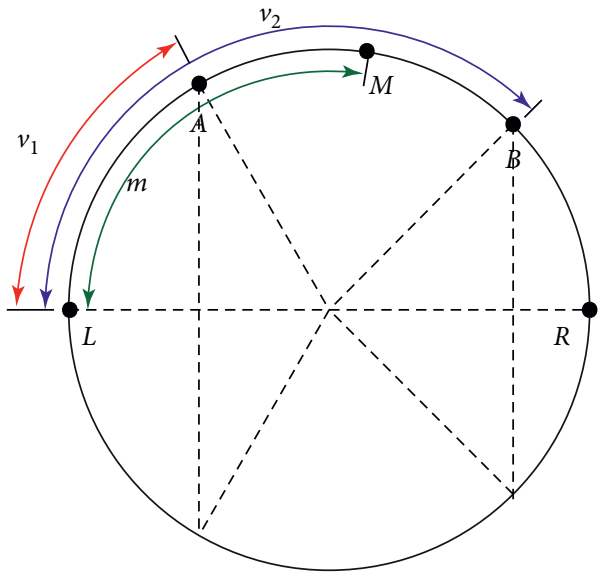

Figure 1: The Salop circular market with attribute differentiation.

pay the deviation cost $d\left(m-v_{1}\right)^{2}$. When customers choose the supplier at point $B$, they need to pay the deviation cost $d\left(v_{2}-m\right)^{2} . d$ refers to the deviation cost rate, which means the psychological utility loss caused by attribute differences [48-53].

When the customer preference $m=m^{*}$, there is no difference among purchasing products provided by two categories of agents. In this case, $m^{*}$ satisfies the equation $p_{1}+d\left(m-v_{1}\right)^{2}=p_{2}+d\left(v_{2}-m\right)^{2}, \quad m^{*}=\left(v_{1}+v_{2}\right) / 2+$ $\left(p_{2}-p_{1}\right) / 2 d\left(v_{2}-v_{1}\right)$. Let $\bar{v}=\left(v_{1}+v_{2}\right) / 2$, which means the average value of attribute location. Let $\Delta v=\left(v_{2}-v_{1}\right)$, which means the difference of attribute location value. For simplicity, it is assumed that the price competition takes place in a limited region, such as the upper part of the circular market. In this region, there is only one customer and the demand equals to 1 , which means $q_{1}+q_{2}=1$. The demand functions of various agricultural business agents could be obtained:

$$
\begin{aligned}
& q_{1}=\bar{v}+\frac{p_{2}-p_{1}}{2 d \Delta v}, \\
& q_{2}=1-\bar{v}-\frac{p_{2}-p_{1}}{2 d \Delta v} .
\end{aligned}
$$

It is worth noting that $\bar{v}$ is the natural purchase volume of agricultural products sold by ordinary farmers, and $1-\bar{v}$ is the natural purchase volume of agricultural products sold by professional cooperatives. Although the agricultural production of ordinary farmers might not have the economies of scale, owing to the development of socialized productive service, as well as the technology spillover of modern agricultural business agents, the production cost of ordinary farmers is gradually decreasing. Therefore, it is assumed that the marginal cost of two categories of agents is $c$. The profit functions of various agricultural business agents could be obtained:

$$
\begin{aligned}
& \pi_{1}=\left(p_{1}-c\right)\left(\bar{v}+\frac{p_{2}-p_{1}}{2 d \Delta v}\right) \\
& \pi_{2}=\left(p_{2}-c\right)\left(1-\bar{v}-\frac{p_{2}-p_{1}}{2 d \Delta v}\right) .
\end{aligned}
$$


By calculating the first derivatives of the price for the profit functions, the marginal profit functions of various agricultural business agents could be obtained:

$$
\begin{aligned}
& \frac{\partial \pi_{1}}{\partial p_{1}}=\bar{v}+\frac{p_{2}-2 p_{1}+c}{2 d \Delta v}, \\
& \frac{\partial \pi_{2}}{\partial p_{2}}=1-\bar{v}+\frac{p_{1}-2 p_{2}+c}{2 d \Delta v} .
\end{aligned}
$$

In order to facilitate the stability analysis of the dynamic system, the second derivatives of the price for the profit functions are calculated for further discussion:

$$
\begin{gathered}
\frac{\partial^{2} \pi_{1}}{\partial p_{1}^{2}}=-\frac{1}{d \Delta v}, \\
\frac{\partial^{2} \pi_{1}}{\partial p_{1} \partial p_{2}}=\frac{1}{2 d \Delta v}, \\
\frac{\partial^{2} \pi_{2}}{\partial p_{2} \partial p_{1}}=\frac{1}{2 d \Delta v}, \\
\frac{\partial^{2} \pi_{2}}{\partial p_{2}^{2}}=-\frac{1}{d \Delta v} .
\end{gathered}
$$

When the equilibrium conditions are $\partial \pi_{1} / \partial p_{1}=0$ and $\partial \pi_{2} / \partial p_{2}=0$, the equilibrium prices of the market are as follows:

$$
\begin{aligned}
& p_{1}^{*}=c+\frac{2}{3} d(1+\bar{v}) \Delta v, \\
& p_{2}^{*}=c+\frac{2}{3} d(2-\bar{v}) \Delta v .
\end{aligned}
$$

Traditional and modern agricultural business agents follow the decision-making principle of bounded rationality and determine the prices for the next period $p_{i}^{n}$, according to the current marginal profit. When the marginal profit is positive, the agent raises the price. When the marginal profit is negative, the agent reduces the price. However, these two kinds of agents are unable to timely and accurately understand the market information, so the price adjustment process has the characteristics of delayed feedback and is restricted by various stakeholders and price regulators [44-51]. Therefore, the price adjustment system of agricultural products with regional brands is set as follows:

$$
\begin{aligned}
& p_{1}^{n}=p_{1}+G_{1} p_{1} \cdot \frac{\partial \pi_{1}}{\partial p_{1}}=p_{1}+G_{1} p_{1}\left(\bar{v}+\frac{p_{2}-2 p_{1}+c}{2 d \Delta v}\right), \\
& p_{2}^{n}=p_{2}+G_{2} p_{2} \cdot \frac{\partial \pi_{2}}{\partial p_{2}}=p_{2}+G_{2} p_{2}\left(1-\bar{v}+\frac{p_{1}-2 p_{2}+c}{2 d \Delta v}\right) .
\end{aligned}
$$

Let $G_{i}=\alpha_{i} /\left(1+\beta_{i}\right) . \alpha_{i}$ is the price adjustment speed. $\beta_{i}$ is the intensity of external pricing regulation. Therefore, $G_{i}$ is the price adjustment speed after the introduction of external price regulation, which increases with the growth of $\alpha_{i}$ and decreases with the growth of $\beta_{i}$.

After calculating the equilibrium solutions of the price competition system, four equilibrium points are obtained, which are $E_{0}=(0,0), E_{1}=(0,[2 d(1-\bar{v}) \Delta v+c] / 2), E_{2}=$ $([2 d \bar{v} \Delta v+c] / 2,0)$, and $E^{*}=\left(p_{1}^{*}, p_{2}^{*}\right)$. In order to analyze the stability of the equilibrium solutions in the dynamic system, it is necessary to figure out the eigenvalues of the Jacobian matrix. The Jacobian matrix of the dynamic system is shown below:

$$
J\left(p_{1}, p_{2}\right)=\left(\begin{array}{cc}
1+G_{1} \cdot \frac{\partial \pi_{1}}{\partial p_{1}}+G_{1} p_{1} \cdot \frac{\partial^{2} \pi_{1}}{\partial p_{1}^{2}} & G_{1} p_{1} \cdot \frac{\partial^{2} \pi_{1}}{\partial p_{1} \partial p_{2}} \\
G_{2} p_{2} \cdot \frac{\partial^{2} \pi_{2}}{\partial p_{2} \partial p_{1}} & 1+G_{2} \cdot \frac{\partial \pi_{2}}{\partial p_{2}}+G_{2} p_{2} \cdot \frac{\partial^{2} \pi_{2}}{\partial p_{2}^{2}}
\end{array}\right) \cdot \begin{array}{cc}
1+G_{1} \cdot\left(\bar{v}+\frac{c}{2 d \Delta v}\right) \\
0 \\
\begin{array}{c}
\text { is as follows, and the Jacobian } \\
\text { igenvalues: } \lambda_{1}=1+G_{1} \cdot(\bar{v}+c /
\end{array}
\end{array} \quad J\left(E_{0}\right)=\left(\begin{array}{cc}
c \\
\text { absolute value of the eigenvalues }
\end{array}\right) .
$$
$2 d \Delta v)$ and $\lambda_{2}=1+G_{2} \cdot(1-\bar{v}+c / 2 d \Delta v)$. Because $\lambda_{1}$ and $\lambda_{2}$ are greater than 1 , so $E_{0}$ is not the stable point of the dynamic system. Similarly, in the Jacobian matrix at $E_{1}$ and $E_{2}$, there are also eigenvalues greater than 1 , so all the boundary equilibrium points are not stable points of the dynamic system:

Because $E^{*}$ is a Nash equilibrium point, various agricultural business agents maximize profits at this point, which means $\partial \pi_{1} / \partial p_{1}=0$ and $\partial \pi_{2} / \partial p_{2}=0$. Thus, the Jacobian matrix at $E^{*}$ could be obtained: 


$$
J\left(E^{*}\right)=\left(\begin{array}{cc}
1-\frac{G_{1} p_{1}^{*}}{d \Delta v} & \frac{G_{1} p_{1}^{*}}{2 d \Delta v} \\
\frac{G_{2} p_{2}^{*}}{2 d \Delta v} & 1-\frac{G_{2} p_{2}^{*}}{d \Delta v}
\end{array}\right) .
$$

The characteristic equation of the dynamic system is $f(\lambda)=\lambda^{2}-T \lambda+D$. In the equation, $T$ is the trace of the Jacobian matrix, $T=2-G_{1} p_{1}^{*} / d \Delta v-G_{2} p_{2}^{*} / d \Delta v$. And, $D$ is the determinant of the Jacobian matrix, $D=\left(1-\left(G_{1} p_{1}^{*} / d \Delta v\right)\right)\left(1-\left(G_{2}\right.\right.$ $\left.\left.p_{2}^{*} / d \Delta v\right)\right)-\left(G_{1} p_{1}^{*} / 2 d \Delta v\right)\left(G_{2} p_{2}^{*} / 2 d \Delta v\right)$. Because the discriminant $T^{2}-4 D \geq 0$, the eigenvalues of the Jacobian matrix are real numbers. If the eigenvalue is within the unit circle, the Nash equilibrium point $E^{*}$ is stable. Therefore, the necessary and sufficient condition of $\left|\lambda_{\mathrm{i}}\right|<1$ is that the Jury stability criterion is satisfied, which means $1-T+D>0,1+T+D$, and $1-D>0$. Because $1-T+D=3 G_{1} p_{1}^{*} G_{2} p_{2}^{*} / 4 d^{2} \Delta v^{2}>0$, it is necessary to make sure that the second and third criterions are satisfied at the same time. So, the parameter needs to meet the following conditions:

$$
\begin{aligned}
& G_{2}\left(\frac{3 G_{1} p_{1}^{*} p_{2}^{*}}{4 d^{2} \Delta v^{2}}-\frac{2 p_{2}^{*}}{d \Delta v}\right)>\frac{2 G_{1} p_{1}^{*}}{d \Delta v}-4, \\
& G_{2}\left(\frac{3 G_{1} p_{1}^{*} p_{2}^{*}}{4 d^{2} \Delta v^{2}}-\frac{p_{2}^{*}}{d}\right)<\frac{G_{1} p_{1}^{*}}{d} .
\end{aligned}
$$

Therefore, a new function $f\left(G_{1}\right)$ could be obtained:

$$
f\left(G_{1}\right)=\frac{\left(2 G_{1} p_{1}^{*} / d \Delta v\right)-4}{\left(3 G_{1} p_{1}^{*} p_{2}^{*} / 4 d^{2} \Delta v^{2}\right)-\left(2 p_{2}^{*} / d \Delta v\right)} .
$$

The stable region of price competition system is surrounded by $f\left(G_{1}\right), G_{1}>0$ and $G_{2}>0$. The intersection points of $f\left(G_{1}\right)$ with $G_{1}$-axis and $G_{2}$-axis are $\left(2 d \Delta v / p_{1}^{*}, 0\right)$ and $\left(0,2 d \Delta v / p_{2}^{*}\right) . E^{*}$ is the equilibrium point of local stability, when $\quad G_{2}<\left(\left(2 G_{1} p_{1}^{*} / d \Delta v\right)-4\right) /$ $\left(\left(3 G_{1} p_{1}^{*} p_{2}^{*} / 4 d^{2} \Delta v^{2}\right)-\left(2 p_{2}^{*} / d \Delta v\right)\right)$.

\section{Simulation and Discussion}

In order to understand the price competition complexity of agricultural products with regional brands when the observation parameters are outside the stable region, the relevant parameters in the above model are assigned, and the numerical simulation is realized by using MATLAB software. The authors analyze the complexity of price competition from the following aspects including price bifurcation, profit bifurcation, maximum Lyapunov index, chaotic singular attractor, and temporal price changing. The model parameters are set as follows: $v_{1}=0.75, v_{2}=0.25, c=1.12$, $d=1.08$, and $G=0.15$. Under this condition, the equilibrium point of the dynamic system is $p_{1}=1.66$ and $p_{2}=1.66$. $v_{1}=0.75$ and $v_{2}=0.25$, which mean that the differentiation degree of product attributes is 0.5 . When the difference between $v_{1}$ and $v_{2}$ is 1 , it means that the product is completely differentiated. However, in fact, due to the self- adaptation and mutual learning of both sides, it is difficult to maximize the relative attribute differences. Therefore, the settings of $v_{1}$ and $v_{2}$ are reasonable. $c$ and $d$ refer to the marginal cost rate and the deviation cost rate. On the one hand, the data from the Yearbook of Brand Agriculture in China shows that the ratio of profits to cost of excellent regional brands can reach about $48 \%$, so when the price of agricultural products is 1.66 , the marginal cost is about 1.12 . On the other hand, the statistical results of China Agricultural Product Price Survey show that when the perceived attributes of agricultural products is completely different from the attribute preference of consumers, at least $65 \%$ discount of transaction price is needed to compensate for the utility loss on average. When the price of agricultural products is 1.66 , the deviation cost rate is about 1.08.

Therefore, the price bifurcation diagram and profit bifurcation diagram of price competition between traditional and modern agricultural business agents could be drawn. In Figure 2, when $G_{1}=G=0.15$ and $G_{2}<1.27$, the price of agricultural products with regional brands is in a stable region. When $G_{1}=G=0.15$ and $1.27<G_{2}<1.60$, the price of agricultural products with regional brands is in the periodic bifurcation region. When $G_{1}=G=0.15$ and $1.60<G_{2}$, the price of agricultural products with regional brands is in a chaotic region, which means that the agricultural products with regional brands completely lose the market equilibrium price. According to Figure 2, it could be concluded that if the cost structure of various agricultural business agents are similar and their excess economic profit is zero, then they could obtain the equilibrium profit of agricultural products with regional brands, and the price fluctuates near the equilibrium point. This is helpful for customers to form stable price expectation and correct brand cognition, which is not conducive to the long-term sales of agricultural products with regional brands. However, when the excess economic profit is positive, the agent would raise the price in the next period to obtain more profits. When the price adjustment speed exceeds a certain threshold, the system would go from the equilibrium state into the periodic or chaotic state. At this time, the disordered price fluctuation makes customers lose their trust in agricultural products with regional brands.

In Figure 3, when $G_{1}=G=0.15$ and $G_{2}<1.27$, the profits of various agricultural business agents are relatively balanced. However, with the continuous increase of $G_{2}$, the price adjustment process would appear as the phenomena of periodic bifurcation and chaos, and the profitability of various agricultural business agents cannot be kept stable. On the one hand, the chaotic state of ordinary farmers' profitability would not only aggravate their opportunistic tendency but also make free-rider problems and negative externality more serious. At the same time, this chaotic state would significantly reduce the welfare of ordinary farmers. On the other hand, due to the large investment, long cycle, and complex market risks in agricultural production, the comparative interests of agriculture in China are relatively low and in a low-end locked state. The chaos of profitability of modern agricultural business agents would force them to withdraw from agriculture gradually. 


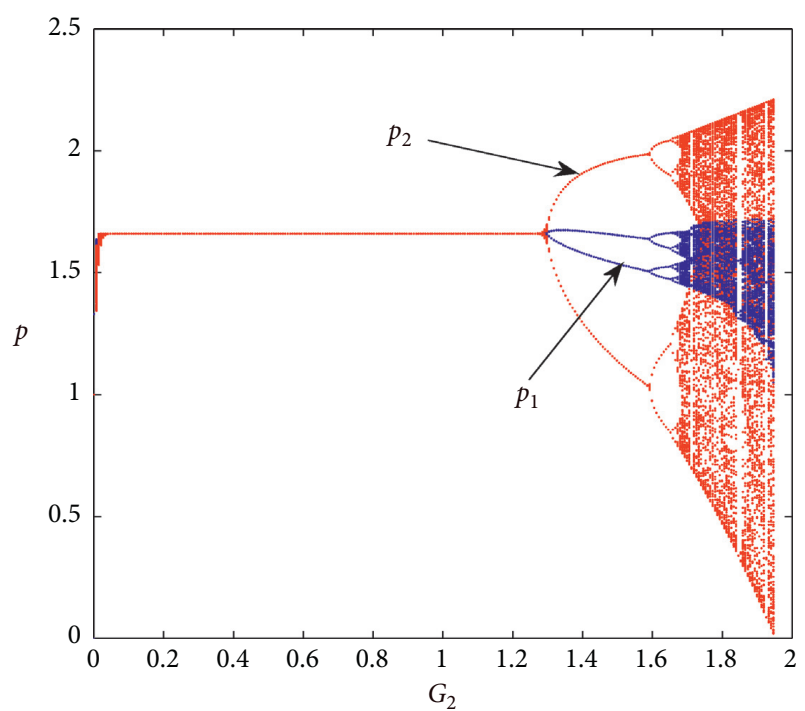

FIgURe 2: Price bifurcation diagram.

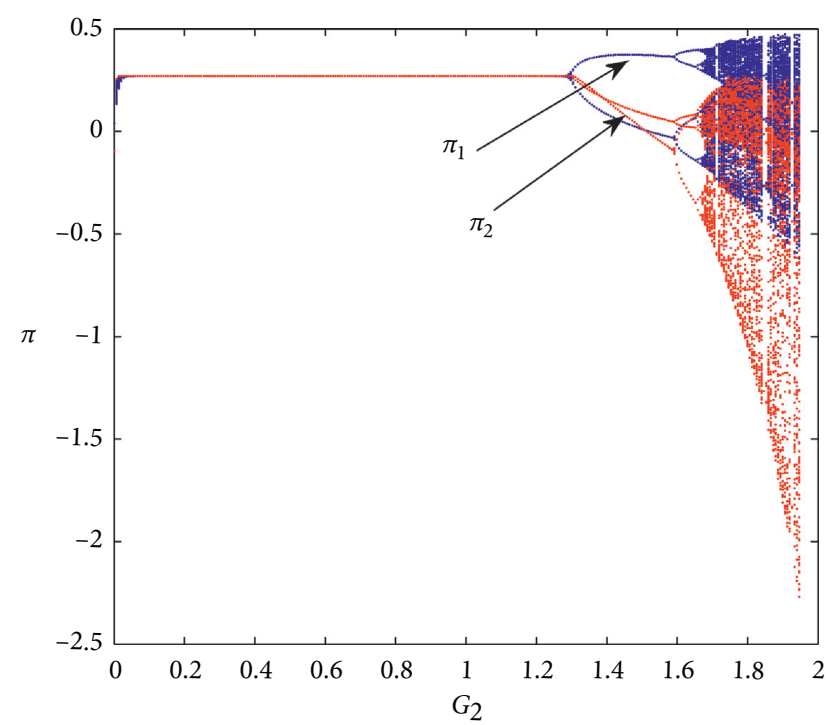

Figure 3: Profit bifurcation diagram.

One of the basic characteristics of chaotic systems is the extreme sensitivity to the initial values, which means the trajectories generated by two similar initial values will be separated exponentially over time. The Lyapunov exponent is an important quantitative index to measure the dynamic characteristics of a system. It represents the average exponential rate of convergence or divergence between adjacent orbits. The maximum Lyapunov exponent could be used to judge whether there is dynamic chaos in the system. It could be seen from Figure 4 that when the maximum Lyapunov exponent equals to zero, the price adjustment system has periodic bifurcation. When the maximum Lyapunov exponent is greater than zero, the price adjustment system enters into chaos.

An important characteristic of chaotic singular attractors is fractional dimension [52]. The definition of the Lyapunov

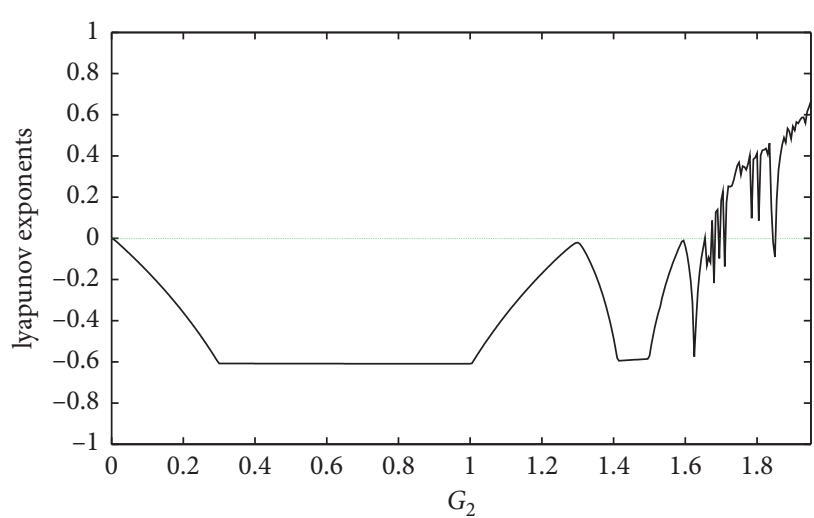

Figure 4: Maximum lyapunov exponent diagram.

dimension given by Kaplan is as follows: $D_{L}=j+\sum_{i=0}^{j} l_{i} /\left|l_{j+1}\right|$. In this equation, $l_{1} \ldots l_{j} \ldots l_{n}$ are Lyapunov exponents, meeting the conditions that $l_{1}>l_{2}>\ldots>l_{j}>\ldots>l_{n} . j$ is the maximum integer making $\sum_{i=1}^{j} l_{i}>0$ and $\sum_{i=1}^{j+1} l_{i}<0$. In the two-dimensional case, the corresponding Lyapunov dimension is $D_{L}=1+\left(l_{1} /\left|l_{2}\right|\right)$, $l_{1}>0, l_{2}\left\langle 0,\left|l_{2}\right|\right\rangle l_{1}$. When the system goes into chaos, the singular attractor of agricultural product price is shown in Figure 5. The parameter settings are as follows: $v_{1}=0.75$, $v_{2}=0.25, c=1.12, d=1.08, G_{1}=0.15$, and $G_{2}=1.8$ :

$$
D_{L}=j+\sum_{i=0}^{j} \frac{l_{i}}{\left|l_{j+1}\right|} .
$$

In order to explain the initial value sensitivity of the price adjustment system of agricultural products with regional brands, the price changing diagram under different initial values is given. In Figures 6 and 7, the initial value of the black polyline is $p_{1}=1.6$ and $p_{2}=1.6$. And, the initial value of red polyline is $p_{1}=1.6001$ and $p_{2}=1.6001$. It could be concluded that the price changing of agricultural products with regional brands is not significant in the early stage. However, as time goes on, the price changing of agricultural products with regional brands under different initial values shows obvious differences, even if the initial value difference is only 0.0001 .

In order to observe whether the delayed feedback control mechanism could regulate the chaotic state of the agricultural product price competition, the chaos control factor is seen as $\beta_{1}=\beta_{2}=\beta$. At the same time, let $p_{1}=1.6, p_{2}=1.6$, $G_{1}=0.15$, and $G_{2}=1.8$. It could be seen from Figure 8 that when $\beta>2.7$, under the effect of delayed feedback control, the price competition of agricultural products with regional brands changes from the chaotic state to the stable state. It could be seen from Figure 9 that when $\beta=0.35, p_{1}=1.6$, and $p_{2}=1.6$, the price finally converges to 1.66 . Therefore, the price regulation of agricultural products with regional brands from industrial associations and government departments could fully achieve the equilibrium. Otherwise, the price competition of agricultural products with regional brands might be in a periodic or chaotic state even if the product difference among various agricultural business agents reaches the maximum. 


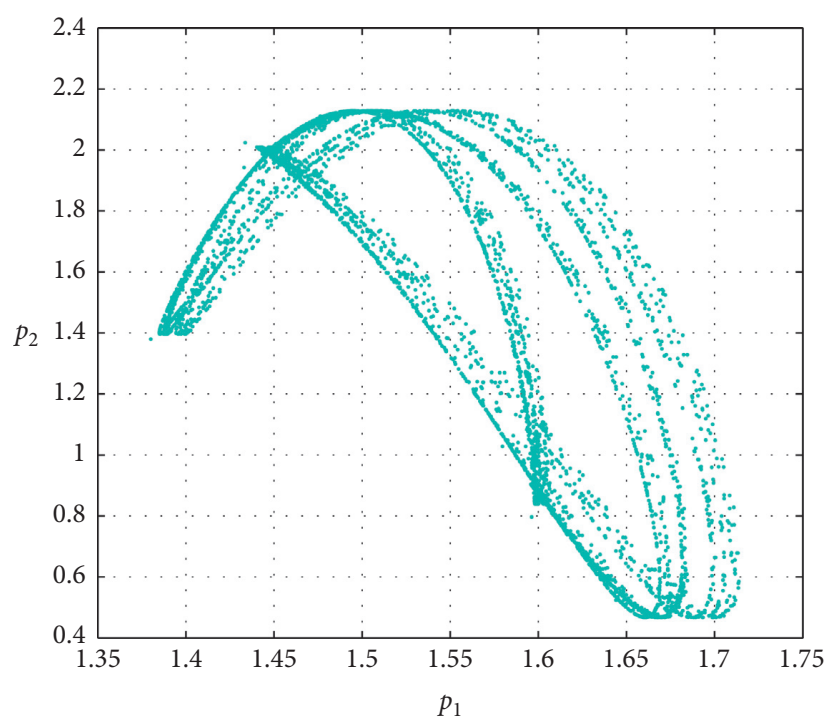

FIgURE 5: Chaotic singular attractor diagram.

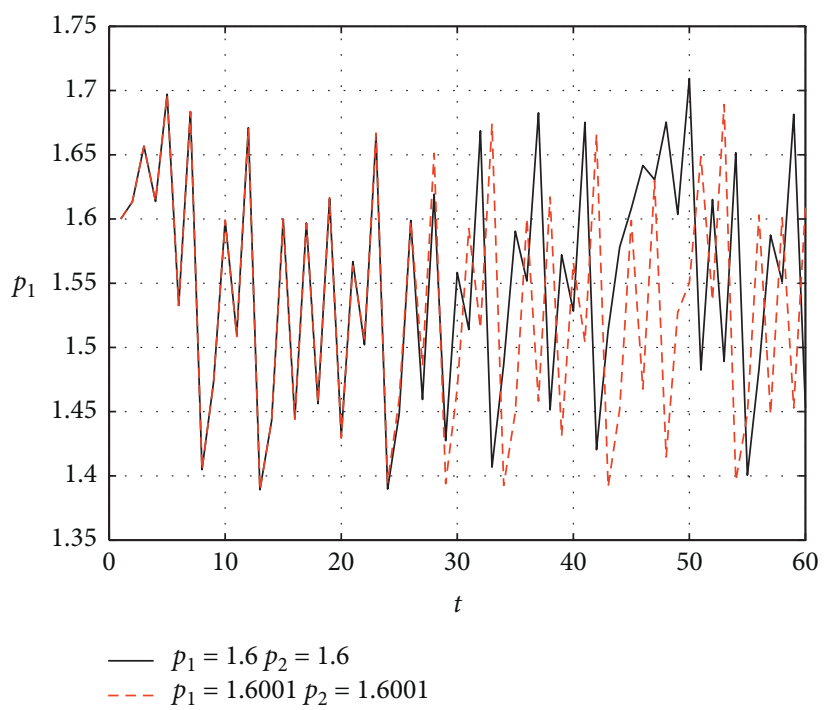

Figure 6: Price changing diagram $\left(p_{1}\right)$.

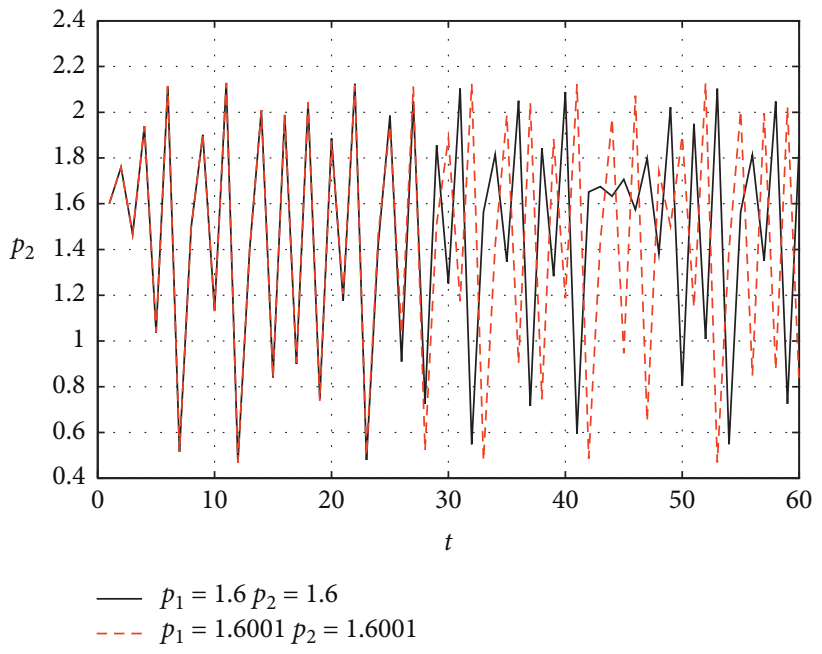

FIgURe 7: Price changing diagram $\left(p_{2}\right)$. 


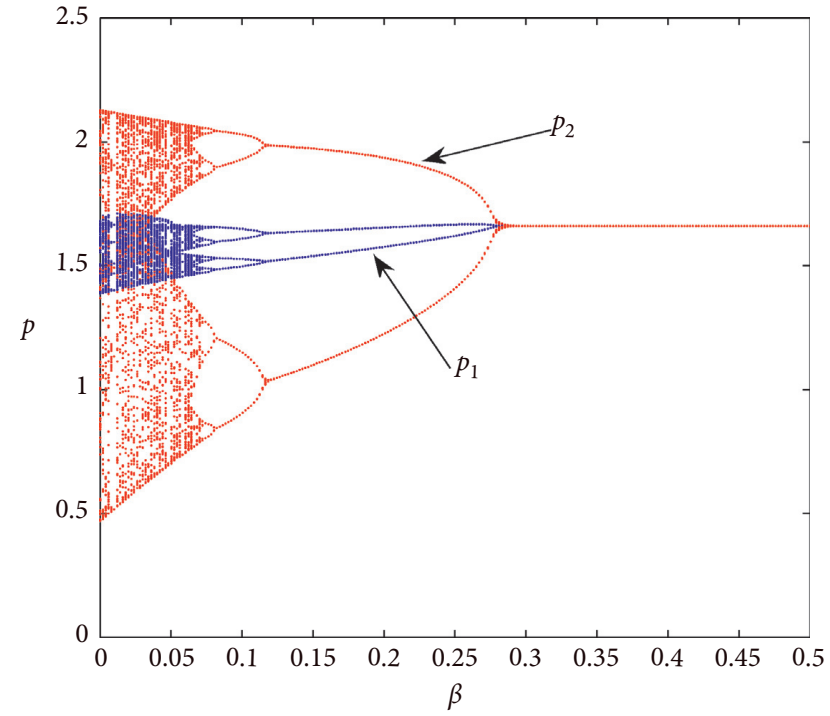

FIgURE 8: Control factor and price bifurcation.



FIGURE 9: Price temporal changing $\left(\beta=0.35, p_{1}=1.6\right.$, and $\left.p_{2}=1.6\right)$.

\section{Conclusion and Enlightenment}

Empirical evidence shows that strengthening the regional brand construction of agricultural products could effectively promote the development of agricultural modernization and supply-side reform and then increase farmers' income. However, due to the attributes of public goods, there are serious free-rider problems in the management of regional brands, which lead to the tragedy of the commons in different forms. The disordered price competition among various agricultural business agents leads to the chaos of agricultural products' prices, which makes it difficult for the customers to form stable price expectations and correct brand recognition, hindering the sales of regional brand agricultural products. Using the Salop circular market model with bounded rationality and delayed feedback, this paper discusses the price competition complexity of regional brand agricultural products. The results show that when the price adjustment speed of various agricultural business agents exceeds the stable region, even if they realize the product differentiation, the pricing system of regional brand agricultural products would also appear as the phenomena of periodic bifurcation or chaos. The greater the price adjustment speed of agricultural producers, the higher the complexity of agricultural product pricing system. However, the delayed feedback control imposed by industrial associations and government departments could make the agricultural product pricing system in the chaos state turn to the equilibrium state so that the agricultural business agents could choose a reasonable price. And, increasing the product portfolio and differentiation degree of agricultural producers could enhance the stability of the system.

\section{Conflicts of Interest}

The authors declare that they have no conflicts of interest.

\section{Acknowledgments}

This paper was supported by the Important Project of National Social Science Fund "Research on the Industrial Chain Coordination Mechanism of New Agricultural Agents under the Goal of High-Quality Development" (19BGl150) and Youth Program of Social Science Planning and Research in Shandong Province "The Ambidextrous Governance Mechanism of Farmers' Cooperatives in Shandong Province" (19DGLJ04).

\section{References}

[1] Q. B. Gong and Z. Yang, "Dynamics of sequential pricing game model with bounded rationality," Chinese Journal of Management Science, vol. 28, no. 4, pp. 186-194, 2020.

[2] Z. Zhang and W. Yu, "Complexity of the Hotelling model with bounded rationality rules," Systems Engineering - Theory \& Practice, vol. 35, no. 4, pp. 920-927, 2015.

[3] D. Rand, "Exotic phenomena in games and duopoly models," Journal of Mathematical Economics, vol. 5, no. 2, pp. 173-184, 1978.

[4] R.-A. Dana and L. Montrucchio, "Dynamic complexity in duopoly games," Journal of Economic Theory, vol. 40, no. 1, pp. 40-56, 1986.

[5] D. Furth, "Stability and instability in oligopoly," Journal of Economic Theory, vol. 40, no. 2, pp. 197-228, 1986.

[6] T. Puu, "Book review," Journal of Economic Behavior \& Organization, vol. 37, no. 3, pp. 385-388, 1998.

[7] G. I. Bischi and M. Kopel, "Equilibrium selection in a nonlinear duopoly game with adaptive expectations," Journal of Economic Behavior \& Organization, vol. 46, no. 1, pp. 73-100, 2001.

[8] M. Yassen and H. Agiza, "Analysis of a duopoly game with delayed bounded rationality," Applied Mathematics and Computation, vol. 138, no. 2, pp. 387-402, 2003.

[9] A. Elsadany, "Dynamics of a delayed duopoly game with bounded rationality," Mathematical and Computer Modelling, vol. 52, no. 9, pp. 1479-1489, 2010. 
[10] Y. Peng and Q. Lu, "Complex dynamics analysis for a duopoly Stackelberg game model with bounded rationality," Applied Mathematics and Computation, vol. 271, no. 11, pp. 259-268, 2015.

[11] L. Fanti, L. Gori, C. Mammana et al., "The dynamics of a Bertrand duopoly with differentiated products: synchronization, intermittency and global dynamics," Chaos, Solitons \& Fractals, vol. 52, no. 7, pp. 73-86, 2013.

[12] W. Yu and Y. Yu, "The complexion of dynamic duopoly game with horizontal differentiated products," Economic Modelling, vol. 41, no. 8, pp. 289-297, 2014.

[13] E. Ahmed, A. A. Elsadany, and T. Puu, "On Bertrand duopoly game with differentiated goods," Applied Mathematics and Computation, vol. 251, no. 2, pp. 169-179, 2015.

[14] L. Xie, J. H. Ma, and M. Goh, "Supply chain coordination in the presence of uncertain yield and demand," International Journal of Production Research, vol. 20, no. 5, pp. 1-17, 2020.

[15] J. Ma and L. Xie, "The comparison and complex analysis on dual-channel supply chain under different channel power structures and uncertain demand," Nonlinear Dynamics, vol. 83, no. 3, pp. 1379-1393, 2016.

[16] J. Ma and Y. Liu, "Exact solutions for a generalized nonlinear fractional Fokker-Planck equation," Nonlinear Analysis: Real World Applications, vol. 11, no. 1, pp. 515-521, 2010.

[17] J. Ma and W. Ren, "Complexity and hopf bifurcation analysis on a kind of fractional-order IS-lm macroeconomic system," International Journal of Bifurcation and Chaos, vol. 26, no. 11, Article ID 1650181, 2016.

[18] J. Ma and L. Sun, "Complexity analysis about nonlinear mixed oligopolies game based on production cooperation," IEEE Transactions on Control Systems Technology, vol. 26, no. 4, pp. 1532-1539, 2018.

[19] L. Xie, J. Ma, and H. Han, "Implications of stochastic demand and manufacturers' operational mode on retailer's mixed bundling strategy and its complexity analysis," Applied Mathematical Modelling, vol. 55, no. 3, pp. 484-501, 2018.

[20] J. H. Ma and R. Hao, "Influence of government regulation on the stability of dual-channel recycling model based on customer expectation," Nonlinear Dynamics, vol. 94, no. 1, pp. 1775-1790, 2018.

[21] T. Xu and J. Ma, "Feed-in tariff or tax-rebate regulation? Dynamic decision model for the solar photovoltaic supply chain," Applied Mathematical Modelling, vol. 89, no. 2, pp. 1106-1123, 2021.

[22] G. Qin and J. H. Ma, "Chaos and hopf bifurcation of a finance system," Nonlinear Dynamics, vol. 58, no. 1, pp. 209-216, 2009.

[23] W. Lou and J. Ma, "Complexity of sales effort and carbon emission reduction effort in a two-parallel household appliance supply chain model," Applied Mathematical Modelling, vol. 64, no. 12, pp. 398-425, 2018.

[24] B. Bao, J. Ma, and M. Goh, "Short- and long-term repeated game behaviours of two parallel supply chains based on government subsidy in the vehicle market," International Journal of Production Research, vol. 58, no. 24, pp. 7507-7530, 2020.

[25] J. H. Ma, Y. M. Hou, W. H. Yang et al., “A time-based pricing game in a competitive vehicle market regarding the intervention of carbon emission reduction," Energy Policy, vol. 142, no. 6, Article ID 11140, 2020.

[26] J. Ma, Y. Hou, Z. Wang et al., "Pricing strategy and coordination of automobile manufacturers based on government intervention and carbon emission reduction," Energy Policy, vol. 148, no. 1, Article ID 111919, 2021.
[27] L. Waltman, N. J. van Eck, R. Dekker et al., "An evolutionary model of price competition among spatially distributed firms," Computational Economics, vol. 42, no. 4, pp. 373-391, 2013.

[28] S. Nasser and D. Turcic, "To commit or not to commit: revisiting quantity vs. price competition in a differentiated industry," Management Science, vol. 62, no. 6, pp. 1719-1733, 2016.

[29] Y. Chen and X. Yin, "Joint price competition and resource allocation for duopoly femtocell market," IEEE Transactions on Vehicular Technology, vol. 67, no. 3, pp. 2491-2500, 2017.

[30] L. Gori and M. Sodini, "Price competition in a nonlinear differentiated duopoly," Chaos, Solitons \& Fractals, vol. 104, no. 11, pp. 557-567, 2017.

[31] S. S. Askar and M. Abouhawwash, "Quantity and price competition in a differentiated triopoly: static and dynamic investigations," Nonlinear Dynamics, vol. 91, no. 12, pp. 1963-1975, 2018.

[32] J. A. Hoyst and K. Urbanowicz, "Chaos control in economical model by time-delayed feedback method," Physica A: Statistical Mechanics and Its Applications, vol. 287, no. 1, pp. 587-598, 2000.

[33] U. Dulleck, R. Kerschbamer, and M. Sutter, "The economics of credence goods: an experiment on the role of liability, verifiability, reputation, and competition," American Economic Review, vol. 101, no. 2, pp. 526-555, 2011.

[34] W. Lee, R. Schober, and V. W. S. Wong, "An analysis of price competition in heterogeneous electric vehicle charging stations," IEEE Transactions on Smart Grid, vol. 10, no. 4, pp. 3990-4002, 2019.

[35] L. Karp, "Provision of a public good with multiple dynasties," The Economic Journal, vol. 127, no. 607, pp. 2641-2664, 2017.

[36] U. Fischbacher and S. Gächter, "Social preferences, beliefs, and the dynamics of free riding in public goods experiments," American Economic Review, vol. 100, no. 1, pp. 541-556, 2010.

[37] J.-B. Sheu, "Airline ambidextrous competition under an emissions trading scheme - a reference-dependent behavioral perspective," Transportation Research Part B: Methodological, vol. 60, no. 2, pp. 115-145, 2014.

[38] J.-E. De Bettignies and A. Duchêne, "Product market competition and the financing of new ventures," Management Science, vol. 61, no. 8, pp. 1849-1867, 2015.

[39] L.-L. B. Wu and D. Wu, "Dynamic pricing and risk analytics under competition and stochastic reference price effects," IEEE Transactions on Industrial Informatics, vol. 12, no. 3, pp. 1282-1293, 2016.

[40] K. Sivakumar, "Price-tier competition: distinguishing between intertier competition and intratier competition," Operations Research, vol. 44, no. 5, pp. 499-501, 2004.

[41] P. Heidhues and B. Köszegi, "Competition and price variation when consumers are loss averse," American Economic Review, vol. 98, no. 4, pp. 1245-1268, 2008.

[42] A. De Palma, C. Ordás Criado, and L. M. Randrianarisoa, "When Hotelling meets Vickrey. Service timing and spatial asymmetry in the airline industry," Journal of Urban Economics, vol. 105, no. 5, pp. 88-106, 2018.

[43] K. Zhang and M. Sarvary, "Differentiation with user-generated content," Management Science, vol. 61, no. 4, pp. 898-914, 2015.

[44] S. S. Askar and A. Al-Khedhairi, "Analysis of nonlinear duopoly games with product differentiation: stability," Discrete Dynamics In Nature And Society, vol. 2017, no. 1, Article ID 2585708, 2017. 
[45] S. M. Jiang, D. Xu, and Z. W. Ding, "Dynamics of a duopoly game with two different delay structures," Discrete Dynamics in Nature and Society, vol. 201712 pages, Article ID 2363804, 2017.

[46] H. Yan and X. J. Sun, "Impact of partial time delay on temporal dynamics of watts-strogatz small-world neuronal networks," International Journal of Bifurcation and Chaos, vol. 27, no. 7, Article ID 1750112, 2017.

[47] C. I. H. Velasco, F. E. H. Velasco, and J. M. L. Monsalve, "Nonlinear dynamics analysis of a dissipation system with time delay," International Journal of Bifurcation and Chaos, vol. 28, no. 6, Article ID 1830018, 2018.

[48] X. Su, Y. Wang, S. Duan, and J. Ma, "Detecting chaos from agricultural product price time series," Entropy, vol. 16, no. 12, pp. 6415-6433, 2014.

[49] L. Liu and X. Zhan, "Analysis of financing efficiency of chinese agricultural listed companies based on machine learning," Complexity, vol. 2019, Article ID 9190273, 11 pages, 2019.

[50] X. Su, H. L. Liu, and S. Q. Hou, “The trilateral evolutionary game of agri-food quality in farmer-supermarket direct purchase: a simulation approach," Complexity, vol. 2018, no. 2, Article ID 684185, 2018.

[51] X. Su, S. S. Duan, and H. L. Liu, "Evolutionary games in the agricultural product quality and safety information system: a multiagent simulation approach," Complexity, vol. 2018, no. 2, Article ID 185497, 2018.

[52] K. Pyragas, "Continuous control of chaos by self-controlling feedback," Physics Letters A, vol. 170, no. 6, pp. 421-428, 1992.

[53] L. X. Liu, T. T. Wang, L. Xie et al., "Influencing factors analysis on land-lost farmers' happiness based on the rough DEMATEL method," Discrete Dynamics in Nature and Society, vol. 2020, Article ID 6439476, 10 pages, 2020. 